\title{
Enabling overweight children to improve their food and exercise habits - school nurses counselling in multilingual settings
}

\author{
Maria B Magnusson, Karin Kjellgren and Anna Winkvist
}

\section{Linköping University Post Print}

N.B.: When citing this work, cite the original article.

This is the authors' version of the following article:

Maria B Magnusson, Karin Kjellgren and Anna Winkvist, Enabling overweight children to improve their food and exercise habits - school nurses counselling in multilingual settings, 2012, Journal of Clinical Nursing, (21), 17-18, 2452-2460.

which has been published in final form at:

http://dx.doi.org/10.1111/j.1365-2702.2012.04113.x

Copyright: Blackwell Publishing http://www.blackwellpublishing.com/

Postprint available at: Linköping University Electronic Press http://urn.kb.se/resolve?urn=urn:nbn:se:liu:diva-81823 


\title{
Enabling overweight children to improve their food and
}

\author{
exercise habits - school nurses' counselling in multilingual
}

\section{settings}

\begin{abstract}
Aims and objectives The study aimed at analysing school nurses' counselling of overweight and obese children in settings with many immigrants, focusing on content concerning food and physical activity and how this was communicated.

Background For people with a predisposition for overweight, the weight control process requires cognitive skills. School nurses' counselling of overweight children has the potential to support this process by enabling personal resources in the children and their families. However, there is uncertainty among nurses about how to conduct supportive counselling. Design An explorative design was used when collecting and analysing data.

Method Twenty-two counselling sessions between eight school nurses and 20 overweight children were audio-recorded and analysed using qualitative content analysis. Most of the participating schools represented areas with low socioeconomic status and a high proportion of immigrants and refugees.

Results Less adequate skills in enabling resources in the children and their parents were observed. Concurrently, school nurses provided inadequate explanations about food and physical activity. Topics related to general nutrition models were frequently communicated as general advice instead of individually tailored counselling. Counselling families with other languages and food cultures than the traditional Swedish created additional difficulties. Conclusions Improved nutritional knowledge for nurses may enhance their skills in enabling children's and families' resources. School nurses should be provided with opportunities to cooperate with other professions in counteracting overweight.

Relevance to clinical practice Our findings demonstrate a relationship between content skills and person-centeredness in the counselling. This highlights the importance of interprofessional collaboration to ensure a high quality of lifestyle counselling. School health authorities should give high priority to facilitating school nurses' evidence-based continuing education.
\end{abstract}

Keywords: child, counselling, cultural, enabling, health promotion, immigrants, obesity, overweight, person-centeredness, school nursing

\section{INTRODUCTION}

In most countries, school nurses play a key role in health promotion among children

(Wainwright 2000), including supporting them to attain and/or maintain a healthy weight 
(Kubik et al. 2007). Childhood obesity and overweight (jointly referred to as OW in this article) constitute a global epidemic (Shrewsbury \& Wardle 2008). In most populations, OW is unevenly distributed, with an overrepresentation in low socio-economic groups and certain ethnic groups (Kumanyika 2008, Shrewsbury \& Wardle 2008). The potential of school health care to combat this epidemic is attracting interest from researchers and health care providers (Lobstein \& Baur 2005, Kropski et al. 2008, Della Torre Swiss et al. 2010).

\section{BACKGROUND}

Food intake and physical activity, complex physiological and social processes, are the primary determinants of body weight. For the lay person, understanding the roles of food intake and physical activity in determining body weight may be complicated by contradictory messages from, for example, advertisements (Powell et al. 2007) and the slimming industry (de Beaufort \& Vandamme 2008). Thus, in order to attain and maintain a healthy weight, people with a predisposition for OW require support to learn meaning-making, defined as “...connecting new information with prior knowledge, affected by one's intention, motivation and strategies" (Lee et al. 2008, p 112).

Currently, there is consensus that lifestyle change counselling should be person-centered (McCance et al. 2008), both for ethical and efficiency reasons. Costain \& Croker (2005) write that health care professionals should strive "... to understand how the patient views their problem, and working on potential solutions together to culminate in the patient feeling that they have developed their own realistic plans for change" (p. 92). There is a widespread perception that school nurses' potential for managing obesity has not yet been fully realised. Studies of school nurses' role in managing obesity in Western countries have generated extensive support for using school health services for this purpose. However, there is both uncertainty as to how this should be undertaken and a lack of guidelines ( Clark 2004, Moyers 
et al. 2005, Kubik et al. 2007, Nauta et al. 2009, Müllersdorf et al. 2010). To our knowledge, no studies have focused on school nurses counselling OW children in settings where language and food culture differ from those of the majority population. The aim of this study was to analyse school nurses' counselling of OW children, in settings with many immigrants, focusing on content concerning food and exercise and how this content was communicated.

\section{METHODS}

\section{Design}

An explorative design was used when collecting and analysing data on school nurses' counselling of OW pupils. These data have previously been used to investigate the communicative aspects (i.e. "how?") of the counselling (Magnusson et al. 2009). The results raised questions about food and exercise content (i.e. "what?). Qualitative content analysis was utilised to gain a deeper understanding of these areas (Graneheim \& Lundman 2004, Krippendorff 2004).

\section{Participants}

The inclusion criteria were: counselling session includes weight management discussions, alone or together with parent/s, interpreter and/or relatives; pupil attends primary or secondary school; pupil is overweight or obese, defined as at risk of having a higher BMI than 25 and 30, respectively, at age 18 (Cole et al. 2000). Forty school nurses with key functions in the Gothenburg school health-care organisation were invited to participate in the study; 14 agreed. Eight of the nurses recruited one or more pupils, who were consecutively included in the study. Most of the schools represented areas with a low socioeconomic status and a high proportion of immigrants and refugees. Thirteen of the pupils had at least one parent born outside Sweden. 


\section{Data collection}

The data used in this study consists of 22 audio-recorded counselling sessions between school nurses and OW children, conducted between January 2005 and June 2007. The sessions lasted between 16 and 50 minutes. Audio-recordings of consultations were used to obtain an authentic impression of the interaction between nurse and pupil. The sessions were conducted with only those who would normally be present, i.e. school nurse, pupil and, occasionally, parent/s, other relatives and/or an interpreter. Data were collected until saturation, meaning that additional recordings did not contribute any substantially new information for the crucial parts of the analysis.

\section{Data analysis}

The audio- recorded counselling sessions were transcribed using a broad transcription format capturing pauses and listener support items (Linell 1994). Two of the authors read the transcriptions and listened to the audio recordings repeatedly. Our unit of analysis consisted of a counselling session. The original spoken language was Swedish. We performed all the analyses in Swedish and translated to English in the final version of the manuscript. Transcriptions of the counsellings were imported into QSR NUD*IST Vivo 2.0, a qualitative research software program designed for non-numerical data. Meaning units related to food and exercise were identified and read repeatedly, frequently returning to the recording and/or transcript of each session to assess the context and meaning attached to the utterances. Meaning units were condensed, i.e. shortened while preserving the core (Graneheim \& Lundman 2004). Codes were developed by writing down keywords that captured aspects assessed as relevant to the issues in focus. After all the transcripts were coded, they were recoded based on influences and reflections emanating from working on the entire material and simultaneously documenting the significance of each code (Table 1). 
Table 1 Examples of coding

\begin{tabular}{|l|l|}
\hline Condensed meaning units & Codes \\
\hline $\begin{array}{l}\text { The plate model is good because it involves a lot of } \\
\text { vegetables. }\end{array}$ & $\begin{array}{l}\text { Food as a duty } \\
\text { Structure } \\
\text { Nutritional models }\end{array}$ \\
\hline You can feast on sweets once a week. & $\begin{array}{l}\text { Vagueness about quantity } \\
\text { Structure }\end{array}$ \\
\hline $\begin{array}{l}\text { You eat too much compared with the amount of energy } \\
\text { you get rid of. }\end{array}$ & $\begin{array}{l}\text { Balance between food and physical } \\
\text { activity }\end{array}$ \\
\hline $\begin{array}{l}\text { We have different building blocks. There's fat and there } \\
\text { are proteins and then there are carbohydrates... }\end{array}$ & $\begin{array}{l}\text { Lecturing about food } \\
\text { Fat } \\
\text { Macronutrients }\end{array}$ \\
\hline Remember to eat slowly! & $\begin{array}{l}\text { Eat slowly } \\
\text { Specific advice }\end{array}$ \\
\hline $\begin{array}{l}\text { Your mum knows a lot about vegetables because you } \\
\text { have a lot of vegetables in your diet. }\end{array}$ & $\begin{array}{l}\text { Confusing explanations about food } \\
\text { Assumption about culture }\end{array}$ \\
\hline $\begin{array}{l}\text { Every day after breakfast you could go out and run } \\
\text { round the jogging track once. }\end{array}$ & Physical activity as a duty \\
\hline $\begin{array}{l}\text { Your body needs to move for the same amount of time } \\
\text { that you sit still. }\end{array}$ & $\begin{array}{l}\text { Balance between being sedentary and in } \\
\text { motion }\end{array}$ \\
\hline
\end{tabular}

Codes were grouped into subcategories in joint discussions between all the authors. The emerging categories referred mainly to the manifest level of content. Finally, themes, considered to be threads of underlying meaning throughout the text on an interpretative level, were identified (Graneheim \& Lundman 2004).

\section{Ethical approval}

The study was approved by The Regional Ethics Committee at the University of Gothenburg (Study code 205-04). Participants and, if the pupil was younger than 15, parents were informed about study protocol, both in writing and verbally, before providing written informed consent. It was emphasised that participation was voluntary. The transcripts were 
made anonymous by removing personal information. The participants were assured of confidentiality.

\section{RESULTS}

Eight school nurses, all women and aged between 41 and 53 years, participated in the study. They were all registered nurses with a graduate diploma in specialist nursing in public health or health care for children and adolescents. Of the twenty pupils who participated in the study, one girl and one boy each participated in two counselling sessions and two pupils jointly participated in three counselling sessions. The mean age of the pupils was 11 years (range 816). All the children were either overweight $(n=7)$ or obese $(n=13)$. Among the girls, the majority (six out of eight) were overweight while almost all the participating boys were obese (eleven out of twelve).

The findings from the qualitative analysis are reported by subcategory, category and theme emerging in the analysis.

Two themes, permeating the categories, were identified: "Quality of explanations" and "Enabling children and parents".

\section{Categories}

Human being in equilibrium included ideas about the balance between energy intake and output, as well as considerations about how to recognise and handle bodily cues. This 
Table 2 Themes, categories and subcategories in counsellings between school nurses and overweight and obese children, concerning food and physical activity

\begin{tabular}{|l|l|l|l|l|l|}
\hline THEME & \multicolumn{4}{|l|}{ ENABLING CHILDREN AND PARENTS } \\
\cline { 2 - 6 } & \multicolumn{3}{|l|}{ QUALITY OF EXPLANATIONS } \\
\hline Category & $\begin{array}{l}\text { Human being in } \\
\text { equilibrium }\end{array}$ & Roles of food & $\begin{array}{l}\text { Components of } \\
\text { food and how to } \\
\text { handle them }\end{array}$ & $\begin{array}{l}\text { Need of physical } \\
\text { activity }\end{array}$ & $\begin{array}{l}\text { Controlling } \\
\text { oneself and others }\end{array}$ \\
\hline Subcategory & $\begin{array}{l}\text {-Energy is dangerous } \\
\text {-Energy is good for you } \\
\text {-Energy is } \\
\text { incomprehensible } \\
\text {-Energy has dual } \\
\text { implications } \\
\text {-People are whole } \\
\text { beings }\end{array}$ & $\begin{array}{l}\text {-Food is a resource } \\
\text {-Food is } \\
\text { problematic }\end{array}$ & $\begin{array}{l}\text {-Missed } \\
\text { opportunities } \\
\text {-Seized } \\
\text { opportunities } \\
\text {-Indispensable } \\
\text { messages } \\
\text {-Sugar } \\
\text {-Fat } \\
\text {-Food and obesity }\end{array}$ & $\begin{array}{l}\text {-To enjoy } \\
\text { movement } \\
\text {-Physical activity } \\
\text { is necessary } \\
\text {-Barriers for } \\
\text { physical activity }\end{array}$ & $\begin{array}{l}\text {-Explaining how to } \\
\text { change }\end{array}$ \\
\hline
\end{tabular}


category also included efforts by the nurses to encourage and support the children to develop their sensitivity to hunger and satiety signals.

Roles of food concerned aspects such as the pleasure of eating, the dimension of autonomy in deciding what to eat and drink as well as eating as a duty and ridiculing certain eating behaviours.

The nurses' talk about food, meal patterns and food components in their attempts to provide nutritional knowledge was included in Components of food and how to handle them, most often communicated either by lecturing or by conveying confusing or vague information. When discussing a desirable meal pattern, all nurses followed the guidelines recommending three main meals and one to three smaller meals, such as fruit, daily.

Need for physical activity concerned exercise as pleasurable and necessary for health. Barriers to physical activity were not commonly addressed by the nurses, although severe climate and the cost of some activities (e.g. horseback riding) were discussed.

Controlling oneself and others includes both parents' and children's expectations. A patronising tendency among the nurses when talking to parents was included in this category. One mother responded to this with the comment, "I've been given homework" when the nurse had been lecturing about fat in milk. The nurses tried to strengthen the parental role by pointing out that parents should be involved in children's decisions about, for example, taking second helpings of food. 
In Figure 1, the subcategories have been positioned in relation to the themes and their respective endpoints.

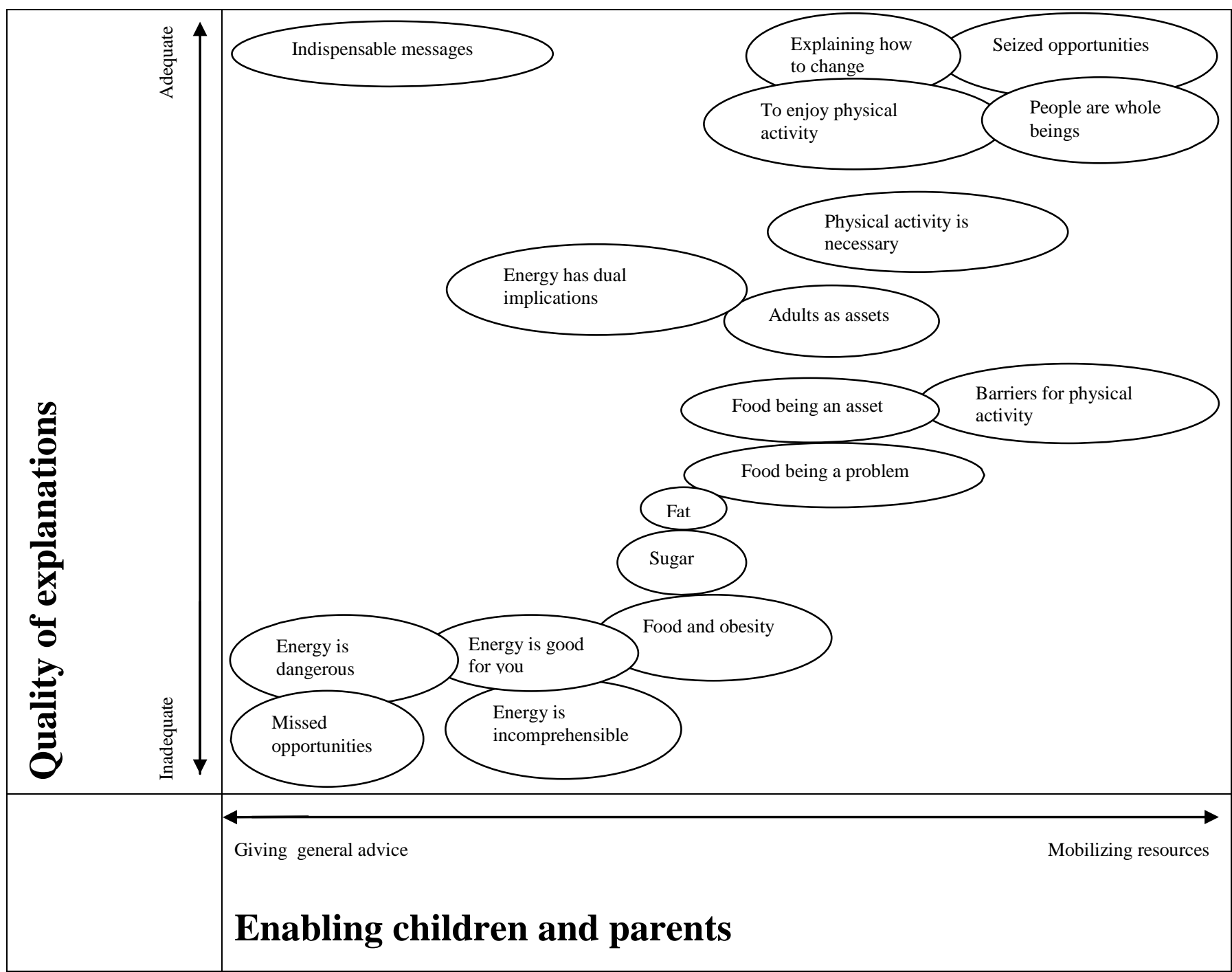

Figure 1 Position of subcategories in relation to themes; in counsellings between school nurses and overweight and obese children concerning food and physical activity

The two themes represent continuums with the endpoints adequate/inadequate and giving general advice/mobilizing resources, respectively. The subcategories are placed in relation to the themes by assessing how they appeared to function in the counselling in terms of context. "Giving general advice" refers to the practice of pointing out a course of preferred action without anchoring it in the childrens'/parents' lifeworld (Magnusson et al. 2009). 


\section{Themes}

\section{Quality of explanations}

In several of the subcategories, inadequate/inappropriate explanations were frequent (Figure 1). The nurses neither explained the relationships between energy, calories, sugar and fat nor between energy and overweight. In six of the counselling sessions, energy was presented by turns in positive and negative terms without clarifying the ambiguity, as exemplified in the following passage:

Nurse: Breakfast is sort of the most important meal in the whole day (ye-es) because it sort of gets you started so you get energy and fuel, doesn't it?...

A few minutes later in the same counselling session, "energy" is used in a negative context:

... And then you have fat, let's say that fat gives you twice as much energy ( $\mathrm{mm}$ ) and if you eat a lot of fat, and particularly saturated fat, then you get an awful lot of energy. And then you've got to get rid of it, because otherwise it remains...you put on weight then. (yes)

Subcategory: Energy is incomprehensible

Placed thematically: Somewhat inappropriate explanation and giving general advice without anchoring it in the child's life-world

One nurse affirmed the statement from a pupil that he ate dark bread "because there is a lot of sugar in white bread". The only nurse who explained that unsaturated fat is healthy but 
saturated fat is not also claimed that unsaturated fat contains about half the energy of saturated fat.

Giving vague advice, leaving much room for interpretation, was common. On several occasions, suitable amounts of sweets and sweetened beverages were described as "only a little, once a week" and, even more vaguely, "once a week you can eat as much as you like". The following quote is from a nurse counselling two teenage girls:

Nurse: So when you realise that you don't get fat from eating, then you're making progress. Because choosing proper... ordinary, proper food doesn't make you fat. Subcategory: Food and obesity Placed thematically: Inappropriate explanation, giving general advice Language shortcomings were common. Advice based on traditional Swedish food habits and cooking traditions further reduced the quality of the counselling of families of foreign origin. For example, "It's much better to cook food in the oven, because then you don't have all that fat" relates to Swedish cooking, in which oven-based dishes often represent a way of cutting down on the fat content, compared to using a frying pan.

\section{Enabling children and parents}

The endpoint "Giving general advice" was defined as pointing out a course of preferred action on the basis of general knowledge without anchoring it in the actual life-world. This method was most often observed in the cases where general nutritional models were used. Only occasionally, as in the following example, did the nurse adjust the message to personal conditions: 
Nurse: Then you can also think about what we call the plate model...

Mother: He doesn't eat any salad

Nurse: What an exciting job you're going to have now! Because there are loads of vegetables, I'm going to show you the other picture I have here. I'd really like to know which ones you like.

Subcategory: Explaining how to change

Placed thematically: Appropriate explanation, enabling resources (by relying on the competence and curiosity of the child)

When addressing the subject of eating behaviour (frequently occurring within the subcategories People are whole beings, Seized opportunities and Explaining how to change), the nurses generally asked about habits and preferences and initiated a dialogue about spontaneous eating between meals, for example. Changing unhealthy eating behaviour was skilfully supported in the following excerpt, in which the nurse describes the feeling of eating too much as a shared experience. She creates the impression that the changed behaviour she is proposing is easy:

Nurse: So what I want you to do is to take a helping, not a really large helping. And then if you feel like you want a bit more, you say to Mum and Dad, 'I'd like to have a bit more.' And then I want them to answer like this, 'Can you wait 10 minutes and see if you're hungry again?' $[\ldots . . . . . .$.$] and here you'll need help from the grownups at$ home...

Father: Yes, exactly 
Nurse: So that they sort of say: 'No, wait a bit.' So then you can take a bit more food after 15 minutes. Then you can say, 'No I'm a little hungry.' 'Okay', Dad or Mum will say, 'have a pear or a bit more fruit or vegetables, then.' And then they'll have to help you. And then when they say no, then you might get angry.

Father, Yes, exactly

Nurse: "' I want more!' And then it's Mum and Dad's job to help you even more like this, 'No, this is how it's going to be and you know why! It's because we care about you, we love you. And we want you to grow and be healthy.'

Subcategories: Explaining how to change, adults as assets

Placed thematically: Appropriate information, mobilising resources (by using the parents' competence and trusting that child will cooperate)

An interpreter was present at only one of the six sessions in which the parties had difficulty understanding each other. In counselling with children with other maternal languages, when nurses tried to mobilise resources within families, they often failed due to language-related misunderstandings. All the nurses who counselled pupils with immigrant parents acknowledged the fact that food cultures differ, for instance by suggesting that the parent should try to transfer the message in pictures shown to "(his) her kind of cooking" and/or offering generalised advice.

\section{DISCUSSION}

The main finding in this study is that school nurses, when counselling OW pupils, gave inadequate explanations, and had difficulties enabling resources of the children and their 
families. Counselling families with a language and food culture other than the traditional Swedish was associated with additional difficulties.

\section{Intertwined entities, content skills and person-centeredness}

Although research literature acknowledges that the difficulties involved in conducting motivating and reciprocal counselling are multifaceted and persistent in nature, it is commonly taken for granted that health care professionals possess adequate knowledge of the topic under discussion in the counselling (Mishler 1984, Costain \& Croker 2005, de Witte et al. 2006, Maenpaa et al. 2007, Florin et al. 2008,Müllersdorf et al. 2010). However, our findings suggest that improving such knowledge is one step towards making counselling more individually tailored.

When it came to most aspects of food in the categories Human being in equilibrium and Components of food and how to handle them, nurses communicated by means of general advice, while their talk about physical activity and eating behaviour tended to be more individually tailored. The common feature of the two latter topics was that they were not included in any general educational material; this, however, does not mean that there is necessarily a contradiction between mobilising resources and the use of general nutritional models. Rather, our results point to a tendency to use such models as substitutes for tailored information instead of as integrated parts of it.

\section{Explaining basic issues}

To be able to make sense of body weight management, one needs a basic understanding of energy balance. Interestingly, none of the nurses in this study explained this concept or its connections with body weight. The recordings give the impression that nurses assumed that these issues were well-known. An alternative explanation is that some nurses in this study did 
not have a sufficiently deep understanding of energy balance mechanisms to explain them comprehensibly and correctly.

\section{Nutritional knowledge}

The results of this study indicate that there is a need to increase nurses' competence in the area of nutrition. A report on nutritional information in Sweden confirms this. The curricula for different levels of graduate nursing education, such as the nurses in this study had, generated insufficient competence to communicate relevant nutritional knowledge on an individual level (Callmer 2005). Developing professional skills is one course of action; another is to facilitate cooperation. A method for professionals to share competences was provided by Melin \& Lenner (2008) who proposed a framework allowing nurses to give advice to OW children on the basis of a questionnaire drawn up by a dietician and a physiotherapist.

In the media, there are numerous pseudo-experts on weight loss methods. However, all the nurses based their advice on established guidelines. This underlines the scientific approach in school nursing, suggesting that reasons for shortcomings described here are to be found in other areas, such as lack of time and limited access to other professional competence. The need for structured curricula in school health care has been confirmed by Morberg et al. (2009).

\section{Language and culture}

Nurses expressed assumptions about food habits in families with non-Swedish origins. However, food acculturation is a complex process, in which details differ from individual to individual (Satia-Abouta et al. 2002). When moving from the Eastern Mediterranean region to the Nordic countries, it is common to reduce vegetable consumption (Wandel et al. 2008) and assumptions such as "you eat a lot of vegetables" may well be wrong. Moreover, 
assuming that a generally "different" food culture exists may be harmful since it can create or strengthen a feeling of deviating from a perceived normality (Kleinman \& Benson 2006).

Like families with Swedish origins, immigrants need concrete advice based on an assessment of the families' actual food habits in the light of their relevance to weight maintenance.

It seems unrealistic that school nurses should be able to optimise nutritional counselling for a broad range of foods, habits, beliefs and cooking methods. Access to professionals with high competence in nutrition is important to ensure that everyone is offered a high quality of care. This is also important from a public health perspective, since individuals from groups with low proficiency in the national language are overrepresented when it comes to several conditions and diseases associated with food and exercise habits (Hjern 2009).

\section{Strengths and limitations}

In order to ensure rigour, the concepts of credibility and dependability were applied (Lincoln \& Guba 1985). By audio-recording the counselling sessions with nobody but the nurse, child and parents (and sometimes an interpreter) present, we documented authentic performances, thus improving credibility. Listening to the recordings repeatedly facilitated the emergence of a multifaceted understanding of the processes.

The strengths include the authors' broad competence and experience: a registered dietician and nurse with experience of counselling OW children and of collaborating with school nurses in this context, a nutritionist with experience of combining quantitative and qualitative methods when evaluating health and nutrition and a nurse who has conducted research on communication and education in different health care settings. Meaning units, codes, categories and themes were discussed and developed jointly by the authors until agreement was reached. This triangulation of researchers from different health science fields thus further increased credibility. 
We used three different types of analyses (theme-oriented discourse analysis, quantitative methods (Magnusson et al. 2009), and qualitative content analysis), of which the latter is presented in this paper. Triangulation provided alternative ways for the data to be exposed (Lincoln \& Guba 1985, Hammersley 2008). The analyses point in the same direction for many counselling sessions: that school nurses use general advice and their own assumptions as starting points, that they dominate the counselling sessions and that content skills (Silverman et al. 2005) constitute an area of improvement.

Our interpretations of the counselling sessions were ventilated in member checks, in which preliminary results were discussed with the nurses. The nurses verified our findings and acknowledged the difficulties in "getting the pupils to talk", as well as noting that it was difficult to convey the amount of information they considered necessary during the very limited time at their disposal.

Additionally, the involvement of all the researchers improved dependability. In qualitative research, theories developed with rigour can be applied beyond the study sample to similar situations, questions and problems (Morse 1999). We believe that the knowledge gained from our findings can be transferred to other counselling settings focusing on lifestyle changes.

The relatively small number of nurses constitutes a limitation of the study. Only 14 of the invited 40 nurses agreed to participate, which raises the question of whether non-participants differed in any systematic way from participants. Since participation reflected an interest in developing methodology for supporting OW pupils, it is probable that the recorded counselling sessions represent a comparatively high level of quality. In view of the fact that our purpose is to explore the nature of school nurses' counselling of OW children, we think that this sample contributes interesting findings, several of which are consistent in the data corpus. It is particularly interesting that almost half of the audio-recordings reveal problems relating to language and food culture, which are highly relevant in this area of research. 
Data collection was extended over a long period of time, the main reason for the delay being difficulties in recruiting nurses and, especially, children and parents. We interpret these difficulties as being symptoms of the stigmatization of obesity in society. Since our research questions, despite the time that has passed, have not been answered by current research and the problems that are outlined in the background have not been solved, the uniqueness of the data may be of great interest.

\section{CONCLUSION}

Our findings demonstrate that inadequate explanations are related to shortcomings in the process of mobilising personal resources in children and parents. Accordingly, we suggest that improved nutritional knowledge among nurses is one way of enhancing person-centered counselling. This study reveals additional difficulties in both information and the enabling process in the case of families with a foreign language and a food culture that differs from the traditional Swedish culture. Given the complexity of childhood obesity, school nurses should be provided with opportunities to cooperate with other professions when meeting the challenge of counteracting obesity and overweight.

\section{RELEVANCE TO CLINICAL PRACTICE}

Our findings demonstrate a relationship between content skills and person-centeredness in counselling. This highlights the importance of inter-professional collaboration to ensure a high quality of lifestyle counselling. School health authorities should give high priority to 
facilitating school nurses' evidence-based continuing education in counselling overweight pupils.

\section{References}

American Dietetic Association. (2006) Position of the American Dietetic Association Individual-, family-, school-, and community-based interventions for pediatric overweight. Journal of American Dietetic Association 106, 925-945.

Callmer E (2005) Health information about food in Sweden (in Swedish) Appendix to Action Plan for healthy dietary habits and increased physical activity. Available at:

http://www.slv.se/upload/dokument/rapporter/mat_naring/uppdrag_underlag_05/halsoinforma tion_om_mat_i_sverige.pdf (accessed 28 March 2011) (In Swedish, summary in English) Swedish National Institute of Public Health and The National Board of Health and Welfare, Stockholm.

Camelon KM, Hadell K, Jamsen PT, Ketonen KJ, Kohtamaki HM, Makimatilla S, Tormala ML. \& Valve RH (1998) The Plate Model: a visual method of teaching meal planning. DAIS Project Group. Diabetes Atherosclerosis Intervention Study. Journal of American Dietetic Association 98, 1155-1158.

Clark A (2004) The role of the school nurse in tackling obesity. Nursing Times 100, 28-29.

Cole TJ, Bellizzi MC, Flegal KM. \& Dietz WH (2000) Establishing a standard definition for child overweight and obesity worldwide: international survey. British Medical Journal 320,1240-1243.

Costain L \& Croker H (2005) Helping individuals to help themselves. The Proceedings of the Nutrition Society 64, 89-96.

de Beaufort I \& Vandamme S (2008) 'No willpower required'. The slimming industry and the right to sell dreams. Medicine and Law, 27, 215-228.

de Wilde JA, van Dommelen P, Middelkoop BJ \& Verkerk PH (2009) Trends in overweight and obesity prevalence in Dutch, Turkish, Moroccan and Surinamese South Asian children in the Netherlands. Archives of Disease in Childhood 94, 795-800.

de Witte L, Schoot T \& Proot I (2006) Development of the client-centred care questionnaire. Journal of Advanced Nursing 56, 62-68.

Della Torre Swiss SB, Akre C \& Suris JC (2010) Obesity prevention opinions of school stakeholders: a qualitative study. Journal of School Health 80, 233-239.

Florin J, Ehrenberg A \& Ehnfors M (2008) Clinical decision-making: predictors of patient participation in nursing care. Journal of Clinical Nursing 17, 2935-2944.

Fogelholm M (2008) How physical activity can work? International Journal of Pediatric Obesity 3 Suppl 1, 10-24.

Graneheim UH \& Lundman B (2004) Qualitative content analysis in nursing research: concepts, procedures and measures to achieve trustworthiness. Nurse Education Today 24, 105-112.

Hammersley M (2008) Troubles with triangulation. In Advances in mixed methods research (Bergman, MM ed.), Sage Publications, London, pp 22-36. 
Hjern A (2009) Migration and health (In Swedish). In Folkhälsorapport 2009 (Report on Public Health. In Swedish, summary in English) The National Board of Health and Welfare, Stockholm.

King CA, Meadows BB, Engelke MK \& Swanson M (2006) Prevalence of elevated body mass index and blood pressure in a rural school-aged population: implications for school nurses. Journal of School Health 76, 145-149.

Kleinman A \& Benson P (2006) Anthropology in the Clinic: The Problem of Cultural Competency and How to Fix It. Public Library of Sciences Medicine 3, 1673-1676.

Krippendorff K (2004) Content Analysis. An introduction to its Methodology. $2^{\text {nd }}$ edn.Sage Publications, London, pp 18-21.

Kropski JA, Keckley PH \& Jensen GL (2008) School-based obesity prevention programs: an evidence-based review. Obesity (Silver Spring) 16, 1009-1018.

Kubik MY, Story M \& Davey C (2007) Obesity prevention in schools: current role and future practice of school nurses. Preventive Medicine 44, 504-507.

Kumanyika SK (2008) Environmental influences on childhood obesity: ethnic and cultural influences in context. Physiology and Behaviour 94, 61-70.

Lee HW, Lim KY \& Grabowski BG (2008) Principles and implications for making meaning. In Handbook of research on educational communications and technology. (Spector $\mathrm{M}$ J, Merrill MD, van Merrienboer J \& Driscoll MP, eds) Taylor \& Francis, New York, pp 111-123.

Lincoln YS \& Guba EG (1985) Naturalistic inquiry, London 1985.

Linell P (1994) Transcription of talk and conversations: theory and practice (In Swedish). University of Linköpings Tema kommunikation, Linköping.

Lissner L, Sohlström A, Sundblom E \& Sjöberg A. (2009) Trends in overweight and obesity in Swedish schoolchildren 1999-2005: has the epidemic reached a plateau? Obesity Reviews 11, 553-559.

Lobstein T \& Baur LA (2005) Policies to prevent childhood obesity in the European Union. European Journal of Public Health 15, 576-579.

Maenpaa T, Paavilainen E \& Astedt-Kurki P (2007) Cooperation with school nurses described by Finnish sixth graders. International Journal of Nursing Practitioner 13, 304-309.

Magnusson MB, Hulthén L\& Kjellgren KI (2009) Misunderstandings in multilingual counselling settings involving school nurses and obese/overweight pupils. Communication \& Medicine 6, 153-164.

McCance T, Slater P \& McCormack B (2009) Using the care dimensions inventory as an indicator of person-centred nursing. Journal of Clinical Nursing 18, 409-417.

Melin A \& Lenner RA (2009) Prevention of further weight gain in overweight school children, a pilot study. Scandinavian Journal of Caring Sciences, 23 498-505.

Mishler E G (1984) The dialectics of medical interviews. Ablex Publishing Corporation, Norwood, New Jersey.

Morberg S., Lagerstrom M. \& Dellve, L. (2009) The perceived perceptions of head school nurses in developing school nursing roles within schools. Journal of Nursing Managment 17(7), 813-821.

Morse (1999) Qualitative generalizability. Qualitative Health Research, 9, 5-6.

Moyers P, Bugle L \& Jackson E (2005) Perceptions of school nurses regarding obesity in school-age children. Journal of School Nursing 21, 86-93.

Müllersdorf M, Zuccato LM, Nimborg J \& Eriksson H (2010) Maintaining professional confidence-monitoring work with obese schoolchildren with support of an action plan. Scandinavian Journal of Caring Sciences 24, 131-138. 
Nauta C, Byrne C \& Wesley Y (2009) School nurses and childhood obesity: an investigation of knowledge and practice among school nurses as they relate to childhood obesity. Issues in Comprehensive Pediatric Nursing 32, 16-30.

Neumark-Sztainer D, Wall M, Story M \& Sherwood NE (2009) Five-year longitudinal predictive factors for disordered eating in a population-based sample of overweight adolescents: implications for prevention and treatment. International Journal of Eating Disorders 42, 664-672.

Peters JC, Wyatt HR, Donahoo WT \& Hill JO (2002) From instinct to intellect: the challenge of maintaining healthy weight in the modern world. Obesity Reviews 3, 69-74.

Powell LM, Szczypka G, Chaloupka FJ \& Braunschweig CL (2007) Nutritional content of television food advertisements seen by children and adolescents in the United States. Pediatrics 120, 576-583.

Satia-Abouta J, Patterson RE, Neuhouser ML \& Elder J (2002) Dietary acculturation: applications to nutrition research and dietetics. Journal of American Dietetic Association 102, 1105-1118.

Shrewsbury V \& Wardle J (2008) Socioeconomic status and adiposity in childhood: a systematic review of cross-sectional studies 1990-2005. Obesity (Silver Spring), 16, 275-284.

Silverman J, Kurtz S \& Draper J (2005) Skills for communicating with patients. $2^{\text {nd }}$ edn. Radcliffe Publishing Ltd, Oxford.

Wainwright P, Thomas J, \& Jones M (2000) Health promotion and the role of the school nurse: a systematic review. Journal of Advanced Nursing 32, 1083-1091.

Wandel M, Råberg M, Kumar B \& Holmboe-Ottesen G. (2008) Changes in food habits after migration among South Asians settled in Oslo: the effect of demographic, socioeconomic and integration factors. Appetite 50, 376-385. 
Table 1 Examples of coding

\begin{tabular}{|l|l}
\hline Condensed meaning units & Codes \\
\hline $\begin{array}{l}\text { The plate model is good because it involves a lot of } \\
\text { vegetables. }\end{array}$ & $\begin{array}{l}\text { Food as a duty } \\
\text { Structure } \\
\text { Nutritional models }\end{array}$ \\
\hline You can feast on sweets once a week. & $\begin{array}{l}\text { Vagueness about quantity } \\
\text { Structure }\end{array}$ \\
\hline $\begin{array}{l}\text { You eat too much compared with the amount of energy } \\
\text { you get rid of. }\end{array}$ & $\begin{array}{l}\text { Balance between food and physical } \\
\text { activity }\end{array}$ \\
\hline $\begin{array}{l}\text { We have different building blocks. There's fat and there } \\
\text { are proteins and then there are carbohydrates... }\end{array}$ & $\begin{array}{l}\text { Lecturing about food } \\
\text { Fat } \\
\text { Macronutrients }\end{array}$ \\
\hline $\begin{array}{l}\text { Remember to eat slowly! } \\
\text { Sat slowly } \\
\text { Specific advice }\end{array}$ \\
\hline $\begin{array}{l}\text { Your mum knows a lot about vegetables because you } \\
\text { have a lot of vegetables in your diet. }\end{array}$ & $\begin{array}{l}\text { Confusing explanations about food } \\
\text { Assumption about culture }\end{array}$ \\
\hline $\begin{array}{l}\text { Every day after breakfast you could go out and run } \\
\text { round the jogging track once. }\end{array}$ & Physical activity as a duty \\
\hline $\begin{array}{l}\text { Your body needs to move for the same amount of time } \\
\text { that you sit still. }\end{array}$ & $\begin{array}{l}\text { Balance between being sedentary and in } \\
\text { motion }\end{array}$ \\
\hline
\end{tabular}


Table 2 Themes, categories and subcategories in counsellings between school nurses and overweight and obese children, concerning food and physical activity

\begin{tabular}{|c|c|c|c|c|c|}
\hline \multirow[t]{2}{*}{ THEME } & \multicolumn{5}{|c|}{ ENABLING CHILDREN AND PARENTS } \\
\hline & \multicolumn{5}{|c|}{ QUALITY OF EXPLANATIONS } \\
\hline Category & $\begin{array}{l}\text { Human being in } \\
\text { equilibrium }\end{array}$ & Roles of food & $\begin{array}{l}\text { Components of } \\
\text { food and how to } \\
\text { handle them }\end{array}$ & $\begin{array}{l}\text { Need of physical } \\
\text { activity }\end{array}$ & $\begin{array}{l}\text { Controlling } \\
\text { oneself and others }\end{array}$ \\
\hline Subcategory & $\begin{array}{l}\text {-Energy is dangerous } \\
\text {-Energy is good for you } \\
\text {-Energy is } \\
\text { incomprehensible } \\
\text {-Energy has dual } \\
\text { implications } \\
\text {-People are whole } \\
\text { beings }\end{array}$ & $\begin{array}{l}\text {-Food is a resource } \\
\text {-Food is } \\
\text { problematic }\end{array}$ & $\begin{array}{l}\text {-Missed } \\
\text { opportunities } \\
\text {-Seized } \\
\text { opportunities } \\
\text {-Indispensable } \\
\text { messages } \\
\text {-Sugar } \\
\text {-Fat } \\
\text {-Food and obesity }\end{array}$ & $\begin{array}{l}\text {-To enjoy } \\
\text { movement } \\
\text {-Physical activity } \\
\text { is necessary } \\
\text {-Barriers for } \\
\text { physical activity }\end{array}$ & $\begin{array}{l}\text {-Adults as assets } \\
\text {-Explaining how to } \\
\text { change }\end{array}$ \\
\hline
\end{tabular}




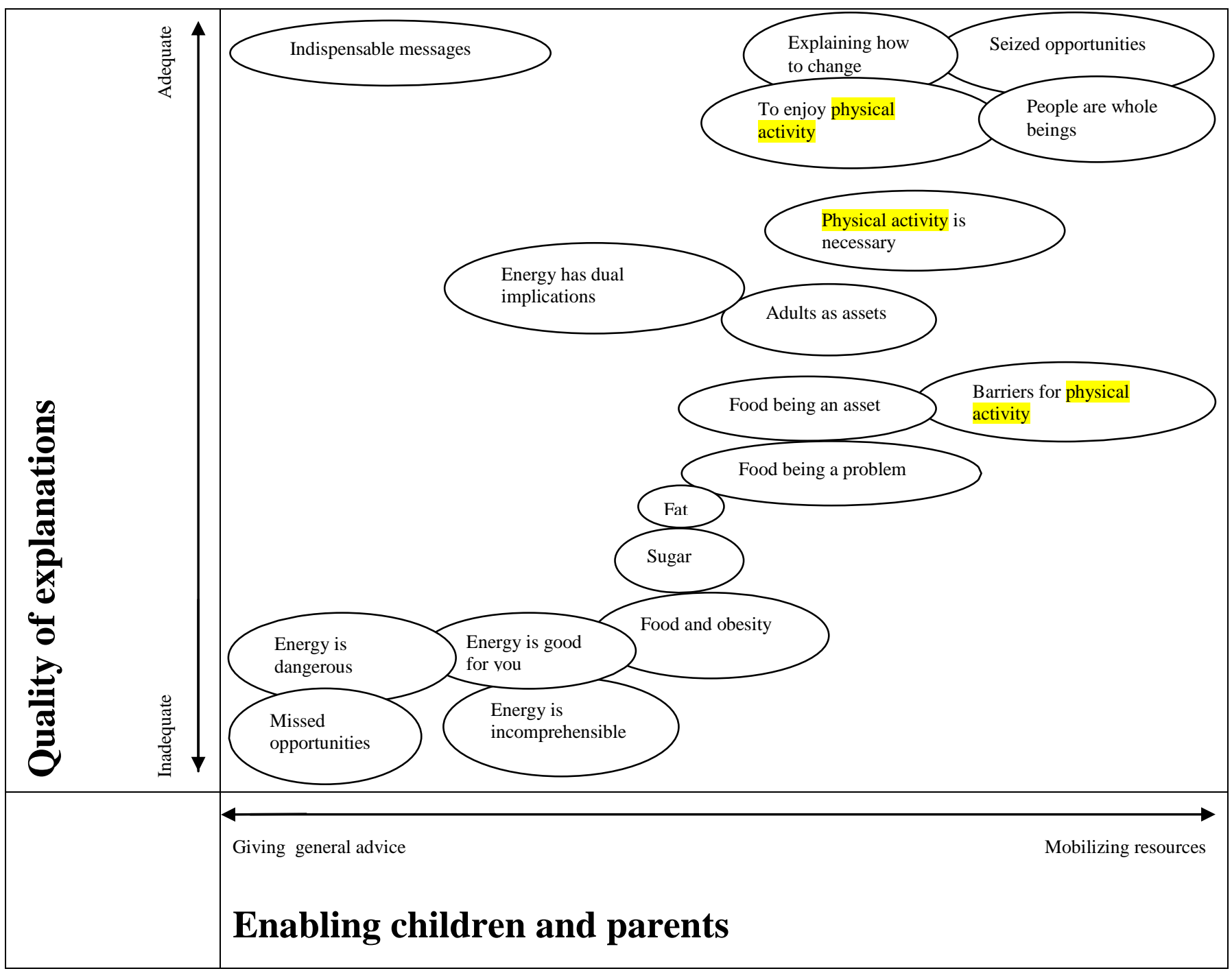

Figure 1 Position of subcategories in relation to themes; in counsellings between school nurses and overweight and obese children concerning food and physical activity

The two themes represent continuums with the endpoints adequate/inadequate and giving general advice/mobilizing resources, respectively. The subcategories are placed in relation to the themes by assessing how they appeared to function in the counselling in terms of context. "Giving general advice" refers to the practice of pointing out a course of preferred action without anchoring it in the children's/parents' lifeworld (Magnusson et al. 2009). 